\title{
Methodological and biological factors explaining the reduction in dental caries in Jamaican school children between 1984 and 1995
}

\author{
Rosalie Warpeha, ${ }^{1}$ Eugenio Beltrán-Aguilar, ${ }^{2}$ and Ramón Báez ${ }^{3}$
}

\begin{abstract}
Objective. To assess the methods used and results found in two surveys, one conducted in 1984 and the other in 1995, that indicated a large reduction in the prevalence and severity of dental caries among children in Jamaica, with special attention focused on methodological differences between the two surveys and the biological factors that may explain the large reduction in caries.

Methods. In 1984 a modified "pathfinder" methodology was used to measure the prevalence and severity of dental caries in 6-, 12-, and 15-year-old children in Jamaica. A similar survey was conducted in 1995. A comparison of the two surveys showed an $84 \%$ reduction in the severity of dental caries at age 12. Both surveys used the same diagnostic criteria and clinical procedures, but the 1984 survey included a higher proportion of rural residents than did the 1995 one.

Results. The data show an epidemiological transition between 1984, when dental caries was highly prevalent and severe, and 1995, when the disease was less prevalent and was concentrated in a smaller proportion of the population.

Conclusions. Most of the reduction in dental caries between 1984 and 1995 is attributable to the introduction, in 1987, of salt fluoridation. While the 1995 survey included fewer rural areas than the 1984 survey did, that does not invalidate the observed reduction in dental caries. The use of fluoride toothpaste and dietary fluoride supplements as well as access to dental health promotion and preventive and curative services do not seem to be major contributors to the reductions observed.
\end{abstract}

Key words: Dental health, surveys, Jamaica, fluoridation.

Prior the 1980s no countrywide data were available on the prevalence and severity of dental caries among children in Jamaica. However, data from
1967-1968 for 11-year-old children in the metropolitan area of Kingston, the capital, showed a mean number of decayed, missing, and filled permanent

\footnotetext{
(In 1984) Jamaica, Ministry of Health, County of Cornwall Health Administration, Montego Bay, Jamaica. Send correspondence to: Dr. Rosalie Warpeha. 357 Grove Street, Waltham, Massachusetts 02453-6018, United States of America; e-mail: roswarpeha@yahoo.com
}

2 Oral epidemiologist, Tucker, Georgia, United States of America.

3 World Health Organization Collaborating Centre in Oral Health, University of Texas, Health Science Center, San Antonio, Texas, United States of America. teeth (DMFT) of 3.4 (1). Therefore, until the mid-1980s, these were the only data that the Ministry of Health had to formulate policies, plan and implement national programs, and train and employ dental personnel for the whole country.

In 1983 the Ministry of Health $(\mathrm{MOH})$ proposed a national caries prevention program utilizing fluoridated salt for human consumption (2). Salt 
fluoridation was the logical choice because there was one local salt producer but several hundred water supplies for a population of 2.3 million people. Between 1984 and 1987 the MOH conducted baseline and feasibility studies, including fluoride levels in water sources, salt usage, fluoride excretion in urine, and oral health status. The oral health status survey was conducted in 1984. Of these baseline studies, only the fluoride excretion data and a summary of the oral health status survey have been published $(2,3)$. The 1984 survey followed the diagnostic criteria and case definition of the World Health Organization (WHO), described in the second (1977) edition of a WHO manual entitled Oral Health Surveys: Basic Methods (4). Sampling followed the "pathfinder" technique recommended by the WHO (4), modified to include a two-stage random selection and an element of proportional representation. The sample included 6-, 12-, and 15-year-old schoolchildren.

In 1995, the MOH, with technical assistance from the Pan American Health Organization Regional Program of Oral Health, implemented a follow-up oral health status survey to evaluate the impact of the salt fluoridation program after 8 years of operation (5). This 1995 survey used a simple random method for sample selection. The investigators compared the mean DMFT at age 12 in the two surveys and found an $84 \%$ reduction in the severity of dental caries. This reduction was attributed to various factors, including the introduction of salt fluoridation in 1987. Upon the release of the 1995 data, independent observers (including one of the authors, EB) raised concerns on the magnitude of such a reduction for the relatively short 8 years that the program had been in effect, 1987 to 1995.

The sampling methods used in the two surveys differed. In addition, to date, no full description of the 1984 survey has been published. Therefore, in this article we describe the methodology used in both surveys, report the full set of results of the 1984 baseline study, and provide methodological and biological explanations for the de- cline in caries prevalence and severity observed between the two surveys.

\section{MATERIALS AND METHODS}

\section{Sampling in the 1984 survey}

In order to draw a sample, the $\mathrm{MOH}$ principal investigator (RW) obtained population distribution data from the Statistical Institute of Jamaica (6) and school enrollments from the Ministry of Education (MOE) (7). The resulting sampling frame represented $100 \%$ of the 12 -year-olds, $77 \%$ of the 6 -yearolds, and $81 \%$ of the 15 -year-olds. The lower percentages of children in the frames for 6- and 15-year-olds were due primarily to three reasons: the existence of over 1400 small pre-primary schools available for children mainly between 3 and 5 years old (these small schools were not sampled because each contained just a few 6-year-olds); the fact that school enrollment was not yet compulsory; and the trend, particularly true for males, of dropping out of school after age 14. All government and private schools were included in the sampling frame (7). Six-year-old children were sampled from 894 schools; 12 - and 15-year-old children were selected from 701 schools.

Additional MOE data classified each school into one of four categoriescity, town, rural, or remote-and also provided information on school attendance on specific days of the week for each of the categories. ${ }^{4-6}$ In 1984, school attendance was not compulsory. In addition, not all parents sent their children to school every day, mostly due to financial constraints or family needs, e.g., market days that required the help of the children. This information guided the scheduling of

\footnotetext{
Jamaica, Ministry of Education, Research Division. Environmental classification of public primary and all-age schools. Kingston, Jamaica: MOE; 1976.

5 Jamaica, Ministry of Education, Research Division. Patterns of attendance, primary and all-age schools. Kingston, Jamaica: MOE; 1976.

6 Jamaica, Ministry of Education, Research Division. Patterns of attendance, secondary schools. Kingston, Jamaica: MOE; 1977.
}

dental examinations so that they would be done on days with higher school attendance. Schools with very small enrollments were not sampled, but these accounted for fewer than 1\% of the students eligible for selection.

In the first stage of sample selection, schools were classified into three strata: "urban," "main towns," or "rural" (6) The urban stratum, the Kingston Metropolitan Region (8), included the parish of Kingston and its contiguous urban portions of the parishes of St. Andrew, St. Catherine, and St. Thomas. The main towns stratum included the remaining 11 parish capitals as well as other towns that, according to census data, had populations ranging from 3600 to 70000 inhabitants, and such urban amenities as piped water, health facilities, local government offices, and trash removal service. The rural stratum included the rest of the country.

In the second stage of selection, a fixed sample size of 400 children was selected for each of the age groups (Table 1). This number of children was considered sufficient to estimate caries prevalence and severity in each stratum and followed the WHO recommendations for countries with suspected high caries prevalence and unknown variability by socioeconomic status (SES) and geographical location. Using a pre-assigned number of 20 children per school, the number of schools assigned to each stratum followed the proportional contribution of each stratum in the total population. Therefore, the number of schools in each stratum provided self-weighting for the computation of national statistics. The total number of schools selected was 39 , as some schools were selected for more than one age group. A sample of 6-year-old children from an additional rural school was examined as a replacement for one rural school that did not initially respond but, in the end, agreed to participate. We decided to keep both schools in the final sample because they had similar disease prevalence.

In the third stage of selection, 20 children were chosen from each se- 
TABLE 1. Number of schools and children by stratum and age group, oral health survey, Jamaica, 1984

\begin{tabular}{|c|c|c|c|c|c|c|c|}
\hline \multirow{3}{*}{$\begin{array}{c}\text { Age } \\
\text { (in years) }\end{array}$} & \multicolumn{6}{|c|}{ Stratum } & \multirow{3}{*}{$\begin{array}{l}\text { Total no. } \\
\text { of children }\end{array}$} \\
\hline & \multicolumn{2}{|c|}{ Urban } & \multicolumn{2}{|c|}{ Main Towns } & \multicolumn{2}{|c|}{ Rural } & \\
\hline & Schools & Children & Schools & Children & Schools & Children & \\
\hline 6 & 7 & 140 & 2 & 40 & 12 & 240 & 420 \\
\hline 12 & 7 & 140 & 3 & 60 & 10 & 200 & 400 \\
\hline 15 & 7 & 140 & 4 & 80 & 9 & 180 & 400 \\
\hline Total no. & $N A^{a}$ & 420 & NA & 180 & NA & 620 & 1220 \\
\hline
\end{tabular}

a NA = not applicable. The total number of schools for all three age groups was 39, as some schools were selected for more than one age group.

lected school and age group, using a table of random numbers. The final sample, a total of 1220 students, by chance represented all types of schools (private and government-funded) in Jamaica. No attempts were made, however, to estimate the probability of selection of each child in the sample. That is, we analyzed the data assuming the same probability of selection for all of the children (simple random sampling selection).

\section{Sampling in the 1995 survey}

In the 1995 survey (5), six geographical regions (sampling units) were selected and classified into three strata (urban, periurban, and rural). Two sampling units were selected with certainty: Kingston (urban stratum) and St. Catherine (periurban stratum). The other four units, comprising the rural stratum, were the parishes of St. Elizabeth, St. Ann, Trelawny, and Portland. The final sample included ten randomly selected schools: two from Kingston, two from the periurban portion of St. Catherine, and six from the four rural parishes. The age groups included were 6 to 8 years, 12 years, and 15 years. The final sample size of 1049 subjects was $24 \%$ urban, $19 \%$ periurban, and $57 \%$ rural.

\section{Examinations in 1984 and in 1995}

In both surveys, the MOE and the school principals granted permission at the national and local level to schedule and implement the surveys.

The 39 schools selected in the 1984 survey were visited by an examination team consisting of one examiner (RW), one assistant, and one recorder, during April to June of 1984 . To obtain maximum participation, the team followed MOE recommendations on school attendance by weekday, including visiting remote rural schools on Tuesdays or Wednesdays.

In 1984 the team followed the ethical standards then applicable, which included parents providing consent for medical and dental screenings at the beginning of the school year. In addition, children were asked to provide verbal consent before the examination. The examination instruments were chemically disinfected following manufacturers' recommendations. The team provided follow-up referrals for children with dental needs and gave oral hygiene instruction as needed. In order to protect the privacy rights of each participant, the dataset for analysis did not include personal identifiers.

The intraoral examinations were carried out using natural light, a plane mouth mirror, and a No. 22 explorer. Following the 1977 WHO diagnostic criteria (4), the assessment of dental caries was primarily visual, using the explorer only to confirm, in suspicious areas, the presence of soft dentin. The one examiner (RW) was an experienced standardized examiner. The examiner conducted blind duplicate examinations on $10 \%$ of the children to assess intraexaminer reliability. From these duplicate examinations, we calculated a kappa statistic of 0.9 , equivalent to near perfect agreement (9). In addition, children of 12 and 15 years of age were examined for periodontal treatment needs, using the Community Periodontal Index of Treatment Needs (CPITN) (10). The results of the CPITN examinations were reported elsewhere (11). Enamel fluorosis was assessed using Dean's index (12) following WHO recommendations (4). Data from the original data entry forms were entered into a customized program using the Epi Info software program (13), and data analysis was done using SAS computer software (14).

The diagnostic criteria and case definition used in the 1995 survey were those described in the 4th edition of WHO's Oral health surveys: basic methods (15), with one exception. Dental explorers rather than periodontal probes were used to assess the presence of carious lesions, in order to allow comparisons with the 1984 survey results. Additional information regarding the 1995 survey is reported elsewhere (5).

We calculated the percent reduction (PR) and compound annual percent reduction (CAPR) (16) to evaluate changes in the mean number of decayed, missing, and filled teeth between 1984 and 1995. Finally, we plotted the cumulative distribution of the DMFT at age 12 for both surveys to assess epidemiological changes in the prevalence and severity of dental caries (16).

\section{RESULTS}

\section{4 survey}

Table 2 shows the age-specific prevalence and severity of dental caries in the permanent dentition in 1984. Of the children 6,12 , and 15 years of age, respectively $72 \%, 97 \%$, and $100 \%$ of them had experienced dental caries, defined as having at least one decayed, missing, or filled permanent tooth ("DMFT"). The mean DMFT values increased with age, from 1.7 teeth at age 6 to 9.6 teeth at age 15 . The mean DMFT at age 12 was 6.7 teeth, which included 6.3 de- 
TABLE 2. Age-specific prevalence and severity of dental caries in the permanent dentition of children, oral health survey, Jamaica, 1984

\begin{tabular}{|c|c|c|c|c|c|c|c|c|c|c|}
\hline \multirow{2}{*}{$\begin{array}{l}\text { Age } \\
\text { (in } \\
\text { years) }\end{array}$} & \multirow{2}{*}{$\begin{array}{l}\text { No. of } \\
\text { children }\end{array}$} & \multirow{2}{*}{$\begin{array}{c}\text { Prevalence } \\
(\% \text { DMFT > 0) }\end{array}$} & \multicolumn{2}{|c|}{ Decayed teeth } & \multicolumn{2}{|c|}{ Missing teeth } & \multicolumn{2}{|c|}{ Filled teeth } & \multicolumn{2}{|c|}{ DMFT total ${ }^{2}$} \\
\hline & & & Mean & SD & Mean & SD & Mean & SD & Mean & SD \\
\hline 6 & 420 & 72 & 1.7 & 1.4 & 0.0 & 0.0 & 0.0 & 0.0 & 1.7 & 1.4 \\
\hline 12 & 400 & 97 & 6.3 & 3.4 & 0.2 & 0.6 & 0.2 & 0.8 & 6.7 & 3.6 \\
\hline 15 & 400 & 100 & 8.5 & 4.1 & 0.7 & 1.1 & 0.4 & 1.3 & 9.6 & 4.3 \\
\hline
\end{tabular}

${ }^{a}$ DMFT = number of decayed, missing, and filled teeth in the permanent dentition.

cayed teeth (teeth with untreated carious lesions), 0.2 missing teeth, and 0.2 filled teeth. Decayed teeth represented $89 \%$ of the entire DMFT index at age 15 , $94 \%$ at age 12 , and $100 \%$ at age 6 .

Data were also collected on the number of decayed, missing, and filled teeth in the primary dentition ("dmft") of the 6-year-old children. In that group, $83 \%$ of them had one or more primary teeth with dental caries ( $\mathrm{dmft}$ $>0$, data not shown). The mean $\mathrm{dmft}$ at age 6 was 4.8 teeth (Table 3 ).

Females had higher mean DMFT scores than did males, 7.1 versus 6.2 at age $12(P<0.01)$ and 10.2 versus 9.3 at age $15(P<0.05)$. Children in urban areas had lower mean $\mathrm{dmft}$ and DMFT scores than did children in main towns and rural areas (Table 3). However, only in the case of the dmft at age 6 and the DMFT at age 15 were the differences statistically significant (Table 3).

Between $71 \%$ and $76 \%$ of first and second permanent molars were affected by dental caries at age 12, and between $79 \%$ and $86 \%$ at age 15 (Table 4). Most of these molars were decayed and required restorative treatment; this was around $69 \%$ of these teeth at age 12 , and between $63 \%$ and $81 \%$ at age 15 . Approximately $5 \%$ of the first permanent molars were missing due to dental caries at age 12 , and $13 \%$ at age 15 . In addition, $8 \%$ and $14 \%$ of the first permanent molars at ages 12 and 15, respectively, required extraction because of caries (data not shown).

TABLE 3. Mean number of decayed, missing, and filled teeth in the primary dentition (dmft) and in the permanent dentition (DMFT) of children, by stratum, oral health survey, Jamaica, 1984

\begin{tabular}{|c|c|c|c|c|c|c|c|c|c|}
\hline \multirow{4}{*}{$\begin{array}{c}\text { Age } \\
\text { (in years) }\end{array}$} & \multirow[b]{4}{*}{ Index } & \multicolumn{8}{|c|}{ dmft and DMFT, mean number and $95 \%$ confidence interval $(\mathrm{Cl})$} \\
\hline & & \multicolumn{6}{|c|}{ Stratum } & \multirow{2}{*}{\multicolumn{2}{|c|}{ Overall }} \\
\hline & & \multicolumn{2}{|c|}{ Urban } & \multicolumn{2}{|c|}{ Main towns } & \multicolumn{2}{|c|}{ Rural } & & \\
\hline & & Mean & $95 \% \mathrm{Cl}$ & Mean & $95 \% \mathrm{Cl}$ & Mean & $95 \% \mathrm{Cl}$ & Mean & $95 \% \mathrm{Cl}$ \\
\hline 6 & $\mathrm{dmft}^{\mathrm{a}}$ & 3.9 & $3.3-4.4$ & 5.4 & $4.2-6.5$ & 5.2 & $4.7-5.7$ & 4.8 & $4.4-5.1$ \\
\hline 0 & DMFT & 1.7 & $1.4-1.9$ & 1.9 & $1.5-2.3$ & 1.7 & $1.5-1.9$ & 1.7 & $1.6-1.9$ \\
\hline 12 & DMFT & 6.2 & $5.6-6.8$ & 7.1 & $6.3-8.0$ & 6.9 & $6.4-7.4$ & 6.7 & $6.3-7.0$ \\
\hline 15 & $\mathrm{DMFT}^{\mathrm{a}}$ & 8.5 & $7.9-9.2$ & 10.6 & $9.6-11.5$ & 10.1 & $9.4-10.7$ & 9.6 & $9.2-10.0$ \\
\hline
\end{tabular}

TABLE 4. Number and percentage of first and second permanent molars by child age and by caries status, oral health survey, Jamaica, $1984^{\mathrm{a}}$

\begin{tabular}{|c|c|c|c|c|c|c|c|c|c|c|}
\hline \multirow{2}{*}{$\begin{array}{c}\text { Age } \\
\text { (in years) }\end{array}$} & \multicolumn{2}{|c|}{ Teeth erupted } & \multicolumn{2}{|c|}{ Teeth decayed } & \multicolumn{2}{|c|}{ Teeth missing } & \multicolumn{2}{|c|}{ Teeth filled } & \multicolumn{2}{|c|}{$\begin{array}{l}\text { Total teeth with } \\
\text { caries experience }\end{array}$} \\
\hline & No. & $\%$ & No. & $\%$ & No. & $\%$ & No. & $\%$ & No. & $\%$ \\
\hline \multicolumn{11}{|l|}{12} \\
\hline 1st molar & 1596 & 99.8 & 1093 & 68.5 & 74 & 4.6 & 40 & 2.5 & 1207 & 75.6 \\
\hline 2nd molar & 1277 & 79.8 & 886 & 69.4 & 6 & 0.5 & 9 & 0.7 & 901 & 70.6 \\
\hline \multicolumn{11}{|l|}{15} \\
\hline 1st molar & 1600 & 100 & 1006 & 62.9 & 203 & 12.7 & 62 & 3.9 & 1271 & 79.4 \\
\hline 2nd molar & 1583 & 98.9 & 1286 & 81.2 & 40 & 2.5 & 32 & 2.0 & 1358 & 85.8 \\
\hline
\end{tabular}


TABLE 5. Mean dmft and DMFT scores (and standard deviation (SD)) and the total percent reduction (PR) and the compound annual percent reduction (CAPR) in those scores among children in all strata of Jamaica and in just the Kingston metropolitan area, oral health surveys, Jamaica, 1984 and $1995^{a}$

\begin{tabular}{|c|c|c|c|c|c|c|c|c|c|c|c|}
\hline \multirow[b]{3}{*}{ Score/age } & \multirow[b]{3}{*}{ Year } & \multicolumn{5}{|c|}{ All strata } & \multicolumn{5}{|c|}{ Urban stratum (Kingston metropolitan area) } \\
\hline & & \multirow[b]{2}{*}{$\begin{array}{l}\text { No. of } \\
\text { children }\end{array}$} & \multirow[b]{2}{*}{ Mean } & \multirow[b]{2}{*}{ SD } & \multicolumn{2}{|c|}{1984 to 1995} & \multirow[b]{2}{*}{$\begin{array}{l}\text { No. of } \\
\text { children }\end{array}$} & \multirow[b]{2}{*}{ Mean } & \multirow[b]{2}{*}{ SD } & \multicolumn{2}{|c|}{1984 to 1995} \\
\hline & & & & & $\begin{array}{l}\mathrm{PR} \\
\%\end{array}$ & $\begin{array}{c}\text { CAPR } \\
\%\end{array}$ & & & & $\begin{array}{c}\text { PR } \\
\%\end{array}$ & $\begin{array}{c}\text { CAPR } \\
\%\end{array}$ \\
\hline $\mathrm{dmft}(6 \mathrm{yr})$ & $\begin{array}{l}1984 \\
1995\end{array}$ & $\begin{array}{l}420 \\
121\end{array}$ & $\begin{array}{l}4.8 \\
2.3\end{array}$ & $\begin{array}{l}3.8 \\
2.8\end{array}$ & 52 & 6.5 & $\begin{array}{r}140 \\
26\end{array}$ & $\begin{array}{l}3.9 \\
2.1\end{array}$ & $\begin{array}{l}3.5 \\
2.7\end{array}$ & 46 & 5.5 \\
\hline DMFT (12 yr) & $\begin{array}{l}1984 \\
1995\end{array}$ & $\begin{array}{l}400 \\
362\end{array}$ & $\begin{array}{l}6.7 \\
1.1\end{array}$ & $\begin{array}{l}3.6 \\
1.8\end{array}$ & 84 & 15.1 & $\begin{array}{r}140 \\
98\end{array}$ & $\begin{array}{l}6.2 \\
0.8\end{array}$ & $\begin{array}{l}3.5 \\
1.6\end{array}$ & 87 & 16.9 \\
\hline DMFT (15 yr) & $\begin{array}{l}1984 \\
1995\end{array}$ & $\begin{array}{l}400 \\
310\end{array}$ & $\begin{array}{l}9.6 \\
3.0\end{array}$ & $\begin{array}{l}4.3 \\
3.0\end{array}$ & 68 & 10.2 & $\begin{array}{r}140 \\
37\end{array}$ & $\begin{array}{l}8.5 \\
2.6\end{array}$ & $\begin{array}{l}3.9 \\
3.2\end{array}$ & 69 & 10.2 \\
\hline
\end{tabular}

a $\mathrm{dmft}=$ number of decayed, missing and filled teeth in the primary dentition; DMFT = number of decayed, missing and filled in the permanent dentition.

Of the 6-, 12-, and 15-year-old children, respectively $50 \%, 32 \%$, and $43 \%$ of them needed urgent dental treatment to alleviate pain or infection. In addition, $27 \%$ of the total sample had palpable lymphadenopathy. Only 23 children showed signs of enamel fluorosis, and 21 of these 23 were classified in the very mild category (12). In the 12 -year-old group the overall prevalence of enamel fluorosis was $2.5 \%$.

\section{5 survey and trends}

More-complete results from the 1995 survey are reported elsewhere (5). The percent reduction (PR) and the compound annual percent reduction (CAPR) between 1984 and 1995 for the $\mathrm{dmft}$ at age 6 and DMFT at ages 12 and 15 are shown in Table 5. For the entire sample (all strata), PR ranged from $52 \%$ to $84 \%$ and CAPR from $6.5 \%$ to $15.1 \%$. The PR for just the urban strata ranged from $46 \%$ to $87 \%$, and the CAPR ranged from $5.5 \%$ to $16.9 \%$.

\section{DISCUSSION}

\section{Trends in dental caries in Jamaica}

In 1984, dental caries was a disease affecting almost all the Jamaican children studied, with a high level of severity. Moreover, most affected teeth

FIGURE 1. Cumulative disease prevalence (DMFT) among 12-year-old Jamaican children in 1984 and in 1995

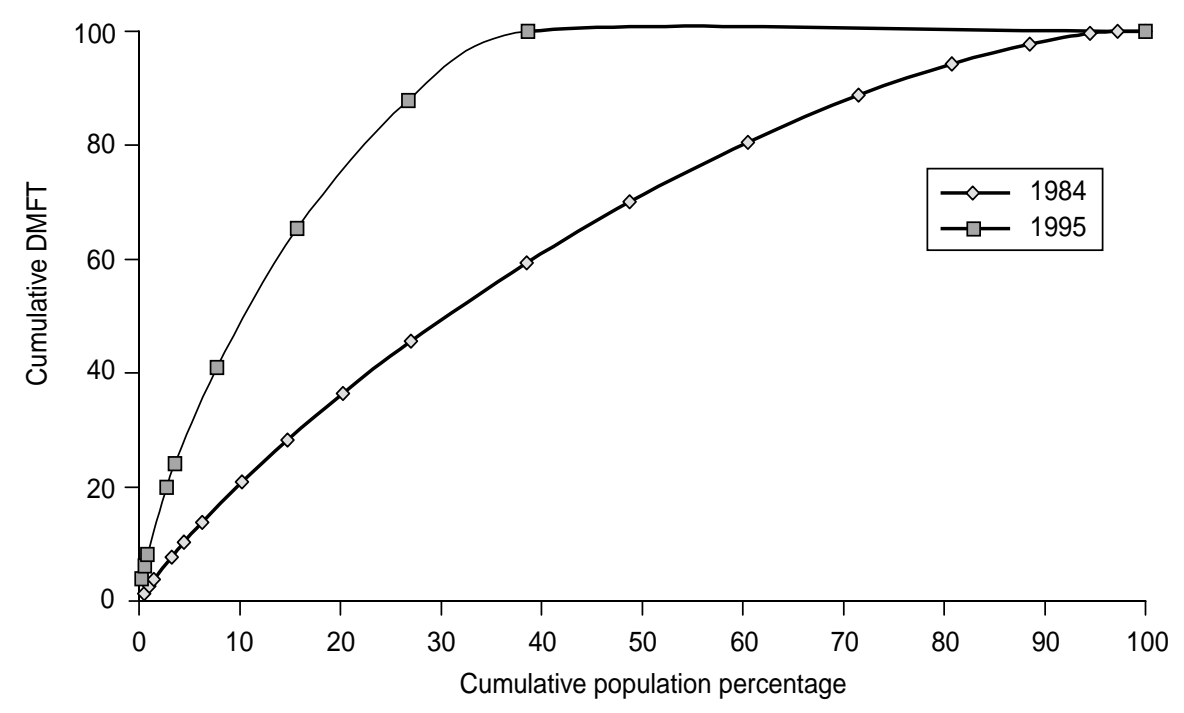

were not receiving restorative treatment. In 1995, dental caries was a disease concentrated in a smaller proportion of the population (5). The epidemiological change between 1984 and 1995 for 12-year-old children is illustrated in Figure 1. In these curves, any point represents the " $x$ " proportion of the population affected by " $y$ " proportion of the cumulative disease, starting with those most affected. For example, in $1984,80 \%$ of the disease occurred in $60 \%$ of the 12-year-old population. In 1995, in contrast, that level was found only in $22 \%$ of the same age cohort.

The decline in disease levels between 1984 and 1995 was $52 \%$ at age 6 , $84 \%$ at age 12 , and $68 \%$ at age 15 (Table $5)$. This reduction has been attributed mainly to the implementation of Jamaica's salt fluoridation program in 1987 (5). The degree of this reduction, however, could be questioned due to different sampling methods, secular trends that included the effect of economic and social development and a higher general health and oral health 
awareness, and the preventive effect of fluoride vehicles such as toothpaste and fluoride supplements. In the following paragraphs, we will address some of these issues.

\section{Methodological factors}

The most reliable way to obtain unbiased estimates of disease prevalence is through probability samples. In a probability sample, each individual has a known, but not necessarily equal, probability of being selected (17). These sampling techniques require the enumeration of eligible individuals into a sampling frame and a random selection, using techniques ranging from simple random sampling (all individuals have the same chance to be selected) to the most complex multistage sampling processes (e.g., cluster, stratified, systematic, and probability proportional to size). The application of these methods requires expert knowledge in sampling and access to reliable information.

In 1971, the WHO, in the first edition of its Oral health surveys: basic methods text, proposed an alternative, "pathfinder" sampling process of stratified cluster sampling $(4,15)$. This technique was developed to obtain convenience samples (not probability-based ones) from populations. The technique aims to include the most important population subgroups having, or likely to have, a full spectrum of disease prevalence, and to collect information from a fixed number of individuals of different age groups in one particular location.

Many investigators who have used the pathfinder method have reported population estimates assuming equal weight to all persons in the sample. Assuming equal weights in a heterogeneous population can produce biased estimates. The WHO pathfinder protocol specifies that weighting could be applied to the aggregate estimates for the different subgroups, according to their percent contribution at the population level. For example, if the mean DMFT values are 3.0 and 2.0 for the rural and urban areas, respec- tively, and the rural area represents $80 \%$ of the entire population, then the national mean DMFT should be equal to 2.8 (computed as $(3.0 \times 0.8)+(2.0 \times$ $0.2)=2.8)$. Assuming equal weights may not be a problem in pathfinder studies where the population is homogeneous in disease levels (18), but this is the exception rather than the rule in the epidemiology of dental caries, especially in developing countries.

There were some differences in sampling design between the 1984 and 1995 Jamaican national surveys. The 1984 survey was a modified pathfinder survey, where careful stratification was carried out before sampling in order to randomly select 39 schools in three strata. A similar technique was used in 1995 to select 10 schools in three strata, but the strata and the criteria used to include the schools in each stratum were different. For example, in 1995 the specific towns in the rural stratum (parishes of St. Elizabeth, St. Ann, Trelawny, and Portland) would have been considered main towns in 1984. In consequence, the 1984 survey included a higher proportion of rural residents than the 1995 survey did.

On the other hand, the urban stratum in both surveys represents more or less the same populations. Table 5 shows that the PR and CAPR for all the strata and for just the urban stratum were of the same magnitude, suggesting that, at least for the urban stratum, the reported differences hold. We calculated PR and CAPR for the other strata (data not shown), and only the PR for age 12 seems to be similar across all the strata, between $83 \%$ and $87 \%$. With the available data, it remains impossible to ascertain the prevalence and severity of dental caries in 1995 in a rural area comparable to the one selected in 1984.

A final comment is warranted on the calculation of national estimates using the pathfinder method. In the 1984 survey, a weighting factor was used to select the number of schools and students in each stratum. The final sample distribution was $34 \%$ urban, $15 \%$ main towns, and $51 \%$ rural, which is almost the same as the distribution in the reference population (33\% urban, $15 \%$ main towns, and $52 \%$ rural). As we have mentioned before, to apply the same weights to every stratum would have yielded biased point estimates. Another way to obtain an unbiased estimate would have been to apply the population weights to the stratum-specific point estimates a posteriori. Whether the weights are applied during the selection process (a priori) or to estimates of equal-size strata (a posteriori) will depend on the size of the sample in each stratum. Applying the weights at the initial process could yield strata with very few individuals. When no weights are available, the investigators should report the full range of data and avoid reporting one value that may be a biased estimate of the entire population.

\section{Biological factors}

If we accept that a reduction in dental caries prevalence occurred between 1984 and 1995, then the next question is whether or not that reduction could be attributed to the salt fluoridation program initiated in 1987. Besides salt fluoridation, four other factors could have contributed to this reduction: the increased use of fluoride toothpaste, a change in diet (including a decline in the use of cariogenic carbohydrates), access to dental preventive services, and exposure to natural fluoride levels in the drinking water. It should be noted, however, that with the absence of a control population (that is, a group of people not consuming fluoridated salt), it is impossible to rule out the effect of a secular trend, as has been described in other populations (16).

The widespread availability of fluoride toothpaste has been credited for the decline of dental caries prevalence in countries that do not have national preventive programs that use systemic fluorides in salt or water (19). Fluoride toothpaste became available in Jamaica in 1968 and, at the time of the 1984 survey, had a market share of $93 \%$, according to surveys conducted 
by the main Jamaican toothpaste manufacturer (20). Therefore, it is unlikely that fluoride toothpaste could have been the main factor in the dental caries reduction observed between 1984 and 1995. It is important to note, however, that fluoride toothpaste and other socioeconomic factors may have contributed to the difference observed in 1984 between urban and rural areas, as toothpaste may have been less frequently used in the rural areas.

By the mid-1980s, sweetened snacks and beverages were much more widely available throughout Jamaica than they had been just one or two decades before. In 1984, sugar cane was chewed in the rural areas, but it is unknown whether its use changed in the years between the two surveys. In the early 1980s the annual sugar consumption in Jamaica was reported as $46 \mathrm{~kg}$ per person (21). If sugar consumption between the surveys increased or remained the same, then sugar consumption does not have an effect in the observed decline in dental caries. If sugar consumption decreased between surveys, then some of the reduction in dental caries could be attributed to lower sugar consumption. However, with the information available, it is impossible to reach any conclusion regarding the role of sugar consumption in the observed reductions of dental caries in Jamaica.

In 1984 the rural areas of Jamaica had less access to preventive and curative dental care than did other areas of the country. This situation improved in the middle to late 1980s as dental auxiliaries, who were persons trained to provide dental health education and dental services at the school level, expanded their services beyond urban areas and reached more of rural Jamaica. It is likely that increased dental health awareness contributed somewhat to the caries reductions indicated by the 1984 and 1995 surveys. Nevertheless, we do not believe that this contribution alone could explain the degree of reduction observed.

Finally, as of $1983,70 \%$ of the people in Jamaica had access to a public water system, with a mean fluoride concentration of $0.22 \mathrm{ppm}$. Drinking water with the highest mean values, between 0.4 and $0.5 \mathrm{ppm}$, reached fewer than 20000 people in 1984 (22). These levels were insufficient for optimal caries prevention at the national level. In addition, $30 \%$ of the population, mostly in rural areas, had private or catchmentrainwater supplies. In 1984, dietary fluoride supplements, multivitamins with fluoride, fluoride rinses, and professionally applied fluoride were not com- monly used. At best, their preventive effects would have benefited the small proportion of the population of a higher SES, mainly in the Kingston area.

We conclude that, despite the differences in sampling between the 1984 and 1995 surveys, and the fact that rural areas were less represented in the 1995 survey, both surveys represented, in the aggregate, the 6-, 12-, and 15-year-old school children in Jamaica at these two points in time. Therefore, the reduction in dental caries observed represented biological factors-including the use of fluoridesin combination with secular trends. However, it is highly probable that the most important factor in this reduction was the consumption, beginning in 1987, of fluoridated salt.

Acknowledgments. We wish to thank the Ministry of Health and the Ministry of Education of Jamaica and the Pan American Health Organization for their support during data collection. Special thanks also go to the Institute of Social and Economic Research of the University of the West Indies and the WHO Collaborating Centre in Oral Health at the University of Texas in San Antonio for assistance in entry and analyses of the data.

\section{REFERENCES}

1. Edwards AN. Dental survey, government aided primary schools, Kingston zones1967-68. Kingston, Jamaica: Ministry of Health; 1969.

2. Warpeha RA. Dental caries and salt fluoridation. Jamaican Pract 1985;5:6-8.

3. Warpeha RA, Marthaler TM. Urinary fluoride excretion in Jamaica in relation to fluoridated salt. Caries Res 1995;29:35-41.

4. World Health Organization. Oral health surveys: basic methods. 2nd ed. Geneva: World Health Organization; 1977.

5. Estupiñán-Day SR, Báez R, Horowitz H, Warpeha R, Sutherland B, Thamer M. Salt fluoridation and dental caries in Jamaica. Comm Dent Oral Epi 2001;29:247-252.

6. Statistical Institute of Jamaica. Population estimates, 1982 census. Kingston, Jamaica: STATIN; 1984.
7. Jamaica, Ministry of Education. Directory of government schools, 1982/83. Kingston, Jamaica: MOE; 1983.

8. Jamaica, National Planning Agency. Urban growth and management study. Kingston, Jamaica: NPA; 1978.

9. Landis JR, Koch GG. The measurement of observer agreement for categorical data. Biometrics 1977;33:158-174.

10. Ainamo J, Barmes DE, Beagrie BG, Cutress TM, Martin J, Sardo Infirri J. Development of the World Health Organization (WHO) Community Periodontal Index of Treatment Needs (CPITN). Int Dent J 1982;32(3):281-291.

11. Warpeha RA, Cochran KP, Jeffcoat MK. Periodontitis in 13-year-old Jamaican children. West Indian Dental J 1995;1:13-15.

12. Dean HT. The investigation of physiological effects by the epidemiological method. In:
Moulton FR, ed. Fluorine and dental health. Washington, D.C.: American Association for the Advancement of Science; 1946. pp. 5-31.

13. Dean AG, Dean JA, Coulombier D, Brendel KA, Smith DC, Burton AH, et al. Epi Info, version 6: a word processing, database, and statistics program for epidemiology on microcomputers. Atlanta, Georgia, United States of America: Centers for Disease Control and Prevention; 1994.

14. SAS Institute Inc. SAS procedures guide, version 6. Cary, North Carolina, United States: SAS Institute Inc.; 1990.

15. World Health Organization. Oral health surveys: basic methods. 4th ed. Geneva: WHO; 1997.

16. Beltrán-Aguilar ED, Estupiñán-Day S, Báez R. Analysis of prevalence and trends of dental caries in the region of the Americas between 
the 1970s and 1980s. Int Dent J 1999;49:322329.

17. Levy P, Lemeshow S. Sampling of populations: methods and applications. 2nd ed. New York: John Wiley \& Sons, Inc.; 1991.

18. Bourgeois D, Leclercq MH, Barmes D. Evaluation of the World Health Organization pathfinder methodology for oral health surveys in industrialized countries. Community Dental Health 1992;9(4):381-384.
19. Burt BA, Eklund SA. Dentistry, dental practice, and the community. 5th ed. Philadelphia: W. B. Saunders; 1999.

20. Colgate Palmolive (Ja) Ltd. Market survey. Kingston, Jamaica: Colgate Palmolive (Ja) Ltd.; 1983.

21. Woodward M, Walker ARP. Sugar consumption and dental caries: evidence from 90 countries. Br Dent J 1994;176(8):297-302.
22. National Water Commission. Fluoride levels in NWC waters. Kingston, Jamaica: NWC; 1983.

Manuscript received on 10 October 2000. Revised version accepted for publication 1 May 2001.
RESUMEN

Factores metodológicos y biológicos que explican la reducción de la caries dental en escolares jamaiquinos entre 1984 y 1995
Objetivos. Evaluar los métodos utilizados y los resultados obtenidos en dos encuestas realizadas en 1984 y 1995 que mostraron una gran reducción de la prevalencia y gravedad de la caries dental en niños jamaiquinos, prestando especial atención a las diferencias metodológicas entre las dos encuestas y a los factores biológicos que podrían explicar la gran disminución de la caries.

Métodos. En 1984 se utilizó una modificación de los métodos de encuesta exploratoria de la Organización Mundial de la Salud para determinar la prevalencia y gravedad de la caries dental en niños jamaiquinos de 6, 12 y 15 años. En 1995 se realizó una encuesta similar.

Resultados. Las dos encuestas emplearon los mismos criterios diagnósticos y procedimientos clínicos, pero la de 1984 incluyó una mayor proporción de residentes rurales que la de 1995. La comparación de ambas encuestas reveló una reducción del $84 \%$ en la gravedad de la caries dental a los 12 años de edad. Los datos muestran una transición epidemiológica entre 1984, cuando la caries dental tenía gran prevalencia y gravedad, y 1995, cuando ambas habían disminuido notablemente.

Conclusiones. La reducción de la caries dental entre 1984 y 1995 es atribuible en su mayor parte a la introducción en 1987 de la fluoración de la sal. Aunque la encuesta de 1995 abarcó menos áreas rurales que la de 1984, esto no invalida la reducción de la caries dental que se observó. El uso de dentífricos fluorados, los suplementos dietéticos de fluoruros y el acceso a los servicios curativos, preventivos y de promoción de la salud dental no parecen haber contribuido de forma importante a la reducción observada. 